\title{
SLCO2B1 genetic polymorphisms in a Korean population: pyrosequencing analyses and comprehensive comparison with other populations
}

\author{
Kyoung-Ah Kim • Hyun-Jin Joo • Hae-Mi Lee • \\ Ji-Young Park
}

Received: 19 February 2013/Accepted: 27 April 2013/Published online: 11 May 2013

(c) The Author(s) 2013. This article is published with open access at Springerlink.com

\begin{abstract}
SLCO2B1, also known as OATP2B1 (Organic Anion Transporter) or OATP-B or SLC21A9, is an organic anion uptake transporter that is encoded by the SLCO2B1 gene. In this study we assessed the frequencies of $S L C O 2 B 1$ polymorphisms in a Korean population using newly developed pyrosequencing methods and compared their frequencies with those in other ethnic groups. We developed pyrosequencing methods to identify the following six SLCO2B1 non-synonymous polymorphisms: c.1175C $>\mathrm{T} \quad(\mathrm{rs} 1621378), \quad$ c.1457C $>\mathrm{T} \quad(\mathrm{rs} 2306168)$, c. $43 \mathrm{C}>\mathrm{T} \quad(\mathrm{rs} 56837383), \quad$ c.935G $>\mathrm{A} \quad(\mathrm{rs} 12422149)$, c.601G $>\mathrm{A}(\mathrm{rs} 35199625)$ and c.644A $>\mathrm{T}(\mathrm{rs} 72559740)$. The allele frequencies of these polymorphisms were analyzed in 227 Korean subjects. The allele frequencies of $S L C O 2 B 1$ polymorphisms in the population tested were as follows: 0.0 for c. $1175 \mathrm{C}>\mathrm{T}, \mathrm{c} .43 \mathrm{C}>\mathrm{T}$ and c.644A $>\mathrm{T}$; 0.2687 for c. $1457 \mathrm{C}>\mathrm{T} ; 0.4273$ for $\mathrm{c} .935 \mathrm{G}>\mathrm{A}$; and 0.0727 for c. $601 \mathrm{G}>\mathrm{A}$. Even though the allele frequencies of the c.1175C $>\mathrm{T}$ and $\mathrm{c} .1457 \mathrm{C}>\mathrm{T}$ polymorphisms were comparable to those in Japanese subjects, the frequencies in this Korean population differed from those in other ethnic groups. The developed pyrosequencing methods are rapid and reliable for detecting non-synonymous $S L C O 2 B 1$ polymorphisms. Large ethnic differences in the frequency of $S L C O 2 B 1$ genetic polymorphisms were noted among ethnic groups. The $S L C O 2 B 1$ polymorphisms at c. $1175 \mathrm{C}>\mathrm{T}, \mathrm{c} .43 \mathrm{C}>\mathrm{T}$ and c.644A $>\mathrm{T}$ were not found in the Korean population while c.1457C $>\mathrm{T}$, c. $935 \mathrm{G}>\mathrm{A}$ and c. $601 \mathrm{G}>\mathrm{A}$ exhibited mostly higher
\end{abstract}

K.-A. Kim · H.-J. Joo · H.-M. Lee · J.-Y. Park ( $\square)$ Department of Clinical Pharmacology and Toxicology, Anam Hospital, Korea University College of Medicine, 126-1, Anamdong 5-ga, Sungbuk-gu, Seoul 136-705, Korea

e-mail: jypark21@korea.ac.kr frequencies in Koreans compared with Finnish, Caucasian and African-American populations.

Keywords SLCO2B1 - OATP2B1 - Pyrosequencing · Pharmacogenetics - Koreans - Ethnic difference

\section{Introduction}

It has recently been recognized that drug pharmacokinetics, efficacy and toxicity are related to the role of drug transporters [1]. Solute Carrier Organic Anion Transporter 2B1 (SLCO2B1), also known as SLC21A9, OATP2B1 and OATP-B, encodes a member of the organic anion transporting polypeptide family of membrane proteins. The SLCO2B1 transporter is expressed at the sinusoidal membrane of hepatocytes in the liver, but also in other tissues including the intestines and heart [2-4]. The SLCO2B1 transporter modulates the levels of endogenous substrates including dehydroepiandrosterone-3-sulfate, estrone-3-sulfate and prostaglandin $E_{2}$ [3-6]. In addition, it acts as a transporter of various therapeutic drugs including montelukast, cyclosporine, fexofenadine, and celiprolol [7-10].

Several polymorphisms have been identified in the $S L C O 2 B 1$ gene, and their frequencies are reported in different ethnic groups. Literature review shows that Nozawa et al. [11] first reported the allele frequencies of $S L C O 2 B 1$ gene, i.e., $S L C O 2 B 1 * 2(\mathrm{c} .1175 \mathrm{C}>\mathrm{T})$ and $S L C O 2 B 1 * 3$ (c.1457C $>\mathrm{T}$ ) in a Japanese population. Although there have been subsequent studies reporting the frequencies of $S L C O 2 B 1$ polymorphisms in different populations, there is still a limited amount of information available regarding ethnic differences in $S L C O 2 B 1$ genetic polymorphisms.

Functionally, the SLCO2B1 c. $1457 \mathrm{C}>\mathrm{T}$ variant was associated with a reduced activity in an in vitro study [11], 
and the c. $601 \mathrm{G}>\mathrm{A}$ polymorphism has been associated with markedly reduced transport activity in vitro [12]. Additionally, it was presented that the c.935G $>$ A polymorphism is associated with a significant reduction of SLCO2B1 activity in vitro and in vivo [8]. Considering that membrane transporters are important modulators of drug disposition [13], it has been established that genetic polymorphisms in genes encoding these transporters may account for inter-individual variability in the pharmacokinetics and pharmacodynamics of drugs.

However, the genetics and functional consequences of SLCO2B1 variants have not been well characterized. Therefore, we analyzed non-synonymous SNPs of the SLCO2B1 gene using pyrosequencing methods. Previous genetic analyses of $S L C O 2 B 1$ variants were conducted either by PCR-RFLP or real-time PCR [1, 8, 11]. Pyrosequencing is a non-electrophoretic, real-time DNA sequencing technology [14]. It involves the hybridization of a primer to a single-stranded PCR template, and initiation of the sequencing analysis by addition of nucleotides. The nucleotides are added sequentially, and through coupled enzymatic reactions, the polymerase-catalyzed incorporation of nucleotides can be monitored as light peaks in a pyrogram. Pyrosequencing is consistent, easy to use, economically viable, and allows for the generation of high throughput analysis with a very high success rate [15].

In this study, we developed pyrosequencing methods that can detect non-synonymous SNPs of SLCO2B1 polymorphisms. Using this technique, we assessed the allelic frequencies of $S L C O 2 B 1$ polymorphisms in a Korean population, and compared these allelic frequencies to those reported for other ethnic groups.

\section{Materials and methods}

Subjects and methods

Genomic DNA samples were obtained from 227 unrelated male and female Korean subjects and written and informed consent was obtained. The protocol for SLCO2B1 DNA analyses was approved by the ethical committee of Anam Hospital, Korea University College of Medicine, Seoul, Korea.

Pyrosequencing method for detection of SLCO2B1 polymorphisms

Genomic DNA was isolated from peripheral leukocytes, as described previously [16, 17]. We developed the pyrosequencing method to identify the following non-synonymous SNPs of the SLCO2B1 gene: c.1175C > T (rs1621378), c.1457C $>\mathrm{T} \quad(\mathrm{rs} 2306168), \quad \mathrm{c} .43 \mathrm{C}>\mathrm{T} \quad(\mathrm{rs} 56837383)$,
c.935G $>$ A (rs12422149) c.601G > A (rs35199625) and c.644A $>$ T (rs72559740) (Table 1). The primers used for the PCR reaction for SLCO2B1 genotyping and pyrosequencing are described in Table 2 . PCR reactions were carried out to amplify sequences to identify each SLCO2B1 SNP using newly developed primer sets after attaching biotin to the $5^{\prime}$ end of each forward (or reverse) primer using PSQ Assay Design software (Pyrosequencing AB, Uppsala, Sweden). The DNA fragments containing SLCO2B1 polymorphic sites were amplified using newly developed primer sets after attaching biotin to the $5^{\prime}$ end of each forward (or reverse) primer using PSQ Assay Design software (Pyrosequencing $\mathrm{AB}$, Uppsala, Sweden). PCR was performed in a reaction volume of $30 \mu \mathrm{l}$ containing genomic DNA (30 ng), $10 \times$ PCR buffer, dNTPs $(0.25 \mathrm{mM}), 10$ pmol primers $(1 \mu \mathrm{l}$ each) and 5U Taq polymerase (iNtRON, Seongnam, Korea). PCR reactions were carried out with an initial denaturation step of $94{ }^{\circ} \mathrm{C}$ for $3 \mathrm{~min}$, followed by 40 cycles of denaturation at $94{ }^{\circ} \mathrm{C}$ for $30 \mathrm{~s}$, annealing at $58-63{ }^{\circ} \mathrm{C}$ for $30 \mathrm{~s}$ and extension at $72{ }^{\circ} \mathrm{C}$ for $30 \mathrm{~s}$. A final termination step was performed at $72{ }^{\circ} \mathrm{C}$ for $5 \mathrm{~min}$ (Table 2).

For pyrosequencing reactions, $25 \mu \mathrm{l}$ of the PCR template in a single well was immobilized by incubation (with shaking at 1,400 rpm, $10 \mathrm{~min}$, room temperature) with a mixture of $5 \mu \mathrm{l}$ streptavidin beads (Streptavidin Sepharose $^{\mathrm{TM}}$ High Performance, GE Healthcare Bio-Science AB, Sweden) and $40 \mu \mathrm{l}$ binding buffer. For primer annealing, $40 \mu \mathrm{l}$ annealing buffer containing $0.4 \mu \mathrm{M}$ sequencing primer was incorporated into each well. For strand separation, all liquid was removed by a Vacuum Prep Workstation (Pyrosequencing AB, Uppsala, Sweden). The beads captured on probes were incubated in $70 \%$ ethanol and the solution was flushed through the filters for $5 \mathrm{~s}$. The beads were then treated with a denaturing solution $(0.2 \mathrm{M} \mathrm{NaOH})$ that was flushed through the filters for $5 \mathrm{~s}$. A wash buffer (10 mM Tris-acetate, $\mathrm{pH}$ 7.6) was used to rinse the beads for $5 \mathrm{~s}$. All liquid was completely drained from the probes, and then the beads were released into a PSQ 96 Plate Low (Pyrosequencing AB, Uppsala, Sweden) containing the sequencing primer. The PSQ 96 Plate Low was heated at $85^{\circ} \mathrm{C}$ for $2 \mathrm{~min}$, and the reactions were allowed to cool to room temperature. The resulting mixture was analyzed on a PSQ 96MA Pyrosequencer (Pyrosequencing AB, Uppsala, Sweden). The accuracy of pyrosequencing was validated by direct DNA sequencing for the randomly selected samples using the same genomic DNA.

Statistical analysis

Genetic equilibrium and linkage disequilibrium were assessed according to the Hardy-Weinberg formula using SNPalyzer ver 7.0 (DYNACOM Co., Ltd, Yokohama, Japan). 
Table 1 Six non-synonymous nucleotide polymorphisms in the SLCO2B1 gene

\begin{tabular}{llll}
\hline SNP & $\begin{array}{l}\text { Reference } \\
\text { number }\end{array}$ & Position & $\begin{array}{l}\text { Amino acid } \\
\text { change }\end{array}$ \\
\hline$S L C O 2 B 1 * 2(\mathrm{c} .1175 \mathrm{C}>\mathrm{T})$ & $\mathrm{rs} 1621378$ & Exon 9 & Thr392Ile \\
$S L C O 2 B 1 * 3(\mathrm{c} .1457 \mathrm{C}>\mathrm{T})$ & $\mathrm{rs} 2306168$ & Exon 10 & Ser486Phe \\
$c .935 G>A$ & $\mathrm{rs} 12422149$ & Exon 7 & Gln312Arg \\
c.43C $>\mathrm{T}$ & $\mathrm{rs56837383}$ & Exon 2 & Pro15Ser \\
$\mathrm{c} .601 \mathrm{G}>\mathrm{A}$ & $\mathrm{rs35199625}$ & Exon 5 & Met201Val \\
$\mathrm{c} .644 \mathrm{~A}>\mathrm{T}$ & $\mathrm{rs} 72559740$ & Exon 5 & Val215Asp \\
\hline
\end{tabular}

\section{Results}

We identified each SNP for c.1175C $>$ T and c.1457C $>$ T using a singlet pyrosequencing method, but multiplex pyrosequencing methods were applied to identify the c. $43 \mathrm{C}>\mathrm{T}$ and c. $935 \mathrm{G}>\mathrm{A}$ or c.601G $>\mathrm{A}$ and c.644A $>$ T SNPs simultaneously. Representative predicted histogram patterns for each genotype are presented in Fig. 1. The assay was designed to generate a specific sequence for each SNP by setting a suitable nucleotide addition order. Nucleotide sequences and pyrograms obtained for each SNP were consistent with the predicted histograms (Fig. 2). The sequencing data obtained from the pyrosequencing method was validated by direct DNA sequencing of each SNP for randomly selected samples, and the results showed $100 \%$ concordance with the multiplex pyrosequencing results, indicating $100 \%$ specificity and sensitivity for the newly developed method.

When we analyzed the six non-synonymous $S L C O 2 B 1$ genetic polymorphisms with the newly developed method in 227 unrelated Korean subjects, the observed allele frequencies of $S L C O 2 B 1$ polymorphisms were as follows: 0.0 for c. $1175 \mathrm{C}>\mathrm{T}$, c. $43 \mathrm{C}>\mathrm{T}$ and c. $644 \mathrm{~A}>\mathrm{T}, 0.2687$ for c. $1457 \mathrm{C}>\mathrm{T}, 0.4273$ for c. $933 \mathrm{G}>\mathrm{A}$, and 0.0727 for c. $601 \mathrm{G}$ $>$ A (Table 3). The allele frequency of c. $935 \mathrm{G}>\mathrm{A}$ in the population tested met Hardy-Weinberg equilibrium $\left(\chi^{2}=\right.$ $0.2795, P=0.597$ for c. $935 \mathrm{G}>\mathrm{A}$ and $\chi^{2}=0.0877, P=$ 0.767 for c. $601 \mathrm{G}>\mathrm{A}$ ) whereas c. $1457 \mathrm{C}>\mathrm{T}$ were not in Hardy-Weinberg equilibrium $\left(\chi^{2}=4.2559, P=0.0391\right)$. When we compared the allele frequencies of SLCO2B1 polymorphisms in this population with those in other ethnic groups, the c.1457C $>\mathrm{T}$ polymorphism frequency were found to be similar to those reported for a Japanese population, but differed from those of other ethnic groups including Caucasians and African-Americans (Table 4).

\section{Discussion}

In this study, we developed a rapid and robust pyrosequencing method to detect six non-synonymous $S L C O 2 B 1$ SNPs and applied this technique to identify these SNPs in a Korean population. We observed that there were substantial differences in allele frequencies of SLCO2B1 genotypes between our Korean sample and other ethnic groups.
Table 2 Oligonucleotide primers used for PCR and pyrosequencing to detect SLCO2B1 polymorphisms

\begin{tabular}{|c|c|c|c|c|c|}
\hline \multirow{18}{*}{$\begin{array}{l}\text { Table } 2 \text { Oligonucleotide } \\
\text { primers used for PCR and } \\
\text { pyrosequencing to detect } \\
\text { SLCO2B1 polymorphisms }\end{array}$} & SNP & Primer & Sequences & Size (bp) & $\operatorname{PCR}\left(\mathrm{Tm} ;{ }^{\circ} \mathrm{C}\right)$ \\
\hline & c. $43 \mathrm{C}>\mathrm{T}$ & Forward & 5'-CTTGGTTCTGAGGTCTAGG-3' & 166 & 58 \\
\hline & & Reverse & B 5'-CCTCCAGGTGTGTTTTCT-3' & & \\
\hline & & Sequencing & $5^{\prime}$-GCGGGTGAGGTACCCCAG-3' & & \\
\hline & c. $601 \mathrm{G}>\mathrm{A}$ & Forward & 5'-AACCCAGCATCTGAGTGT-3' & 145 & 58 \\
\hline & & Reverse & B 5'-GTCCTCACCGAGGTAGAG-3' & & \\
\hline & & Sequencing & $5^{\prime}$-CACAGACCCTGCTGGGC-3' & & \\
\hline & c. $644 \mathrm{~A}>\mathrm{T}$ & Forward & 5'-AACCCAGCATCTGAGTGT-3' & 145 & 58 \\
\hline & & Reverse & B 5'-GTCCTCACCGAGGTAGAG-3' & & \\
\hline & & Sequencing & 5'-TTTGGCATCTCCTACAT-3' & & \\
\hline & c. $935 \mathrm{G}>\mathrm{A}$ & Forward & В 5'-ССССТАСТТСТТСТТССС-3' & 115 & 58 \\
\hline & & Reverse & 5'-GACATGGAGGGAGCTTAC-3' & & \\
\hline & & Sequencing & 5'-TGTGACTGCTAAGACCTTT-3' & & \\
\hline & c. $1175 \mathrm{C}>\mathrm{T}$ & Forward & 5'-GTAGGAGGCTGTGATGGA-3' & 88 & 58 \\
\hline & & Reverse & B 5'-CCAGGTATGCTTGTCATC-3' & & \\
\hline & & Sequencing & $5^{\prime}$-CCAGGAACTTGGGCAGG-3' & & \\
\hline & c. $1457 \mathrm{C}>\mathrm{T}$ & Forward & 5'- ACCCTACTGGTCTTCTCTC-3' & 141 & 63 \\
\hline & & Reverse & B 5'-TGGCAGGGTGTGATGTATT-3' & & \\
\hline $\mathrm{B}=$ biotinylated at the $5^{\prime}$-end & & Sequencing & $5^{\prime}$-CCCACCCTGGGCTGGA-3' & & \\
\hline
\end{tabular}



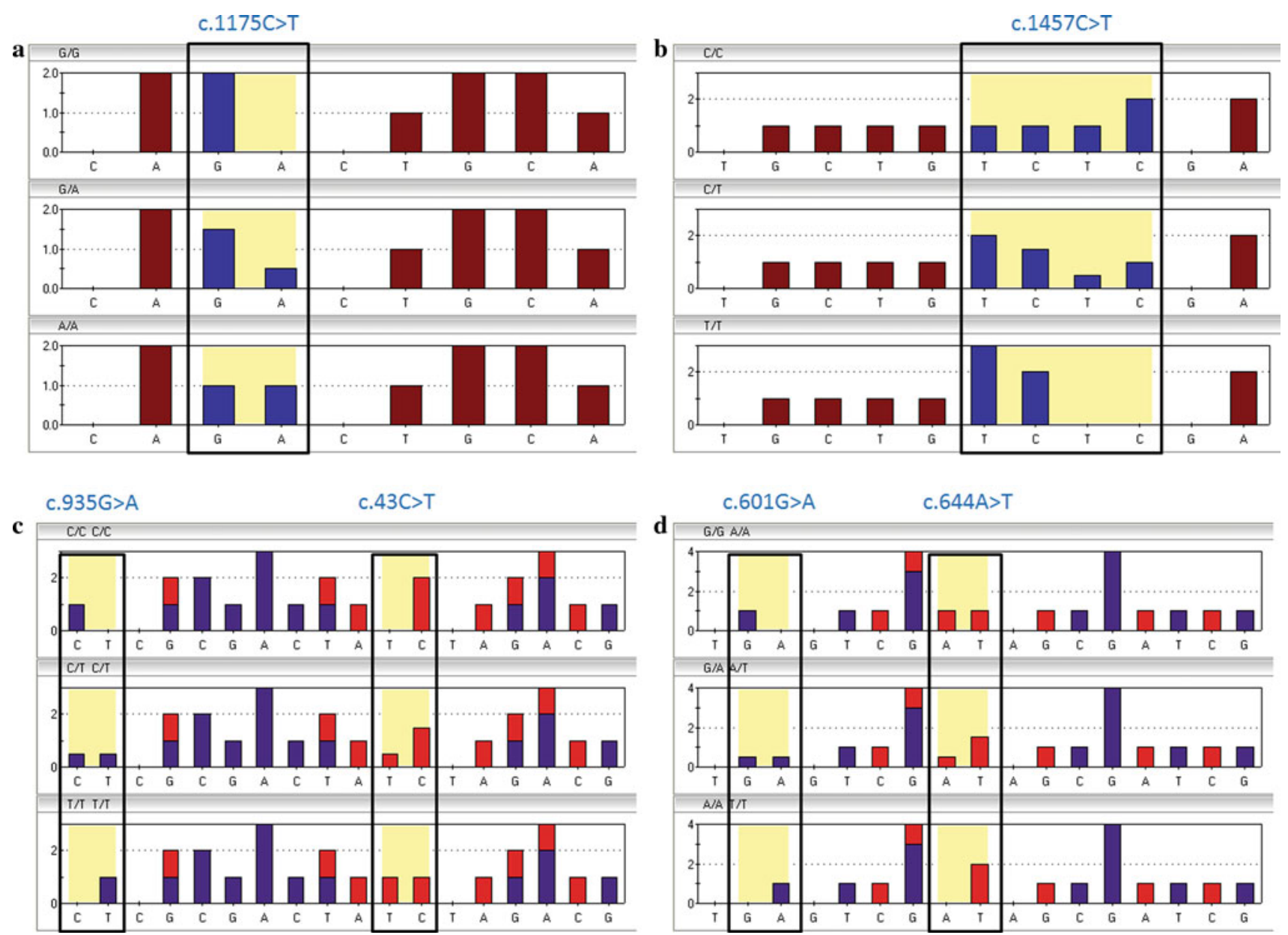

Fig. 1 Pyrosequencing histograms for SLCO2B1 SNPs predicted by pyrosequencing software. Shaded areas represent polymorphic sites to be interrogated. a $\operatorname{SLCO} 2 \mathrm{~B} 1 * 2(\mathrm{c} .1175 \mathrm{C}>\mathrm{T})$, b $S L C O 2 B 1 * 3$

To our knowledge, this is the first study to identify SLCO2B1 polymorphisms using a pyrosequencing method. Previously, SLCO2B1 SNPs were detected through PCRRFLP [7, 11, 18] and real-time PCR [1, 8].

SLCO2B1 is expressed in the liver, spleen, placenta, lungs, kidneys, heart, ovaries, small intestine, and brain [19]. A number of endogenous and exogenous compounds act as substrates of the SLCO2B1 transporter [6, 13]. A number of studies have shown that $S L C O 2 B 1$ SNPs could cause a functional change in SLCO2B1 transport activity. Nozawa and his colleague first reported the role of polymorphic $S L C O 2 B 1$ genes in modulating the expression levels of OATP2B1 proteins in vitro [11]. The protein expression for $S L C O 2 B 1 * 2(\mathrm{c} .1157 \mathrm{C}>\mathrm{T})$ and $S C L O 2 B 1 * 3(\mathrm{c} .1457 \mathrm{C}>\mathrm{T})$ was 71.1 and $42.5 \%$ compared with $S L C O 2 B 1 * I$ (wild type), respectively [11]. Furthermore, c.1457C $>\mathrm{T}$ exhibited decreased transport activity in HEK cells [20]. It has consistently been reported that subjects with the c.1457TT polymorphism exhibit $36 \%$ lower AUC values but $52 \%$ higher oral clearance values for fexofenadine compared with those

(c.1457C > T), c multiplex c.43C > T/c.935G > A and d multiplex c. $601 \mathrm{G}>\mathrm{A} / \mathrm{c} .644 \mathrm{~A}>\mathrm{T}$

with c.1457CC [7]. Asthma patients with the SNP positioned at c. $935 \mathrm{G}>\mathrm{A}$ exhibited a significant reduction in plasma levels of montelukast and reduced permeability to the drug in a MDCKII cell line expressing OATP2B1 [8]. Considering these findings, we believe that genetic polymorphisms of SLCO2B1 play a substantial role in modulation of the pharmacokinetics/pharmacodynamics of SLCO2B1 substrates in humans.

Among the genotypes we screened in this population, we did not find any genetic substitution at c.1175C $>\mathrm{T}$, c. $43 \mathrm{C}>\mathrm{T}$ or $\mathrm{c} .644 \mathrm{~A}>\mathrm{T}$. We attempted to determine whether there is an ethnic difference frequencies of these alleles, but were only able to find one study reporting the frequency of c.1175C $>\mathrm{T}$. Consistent with the present study, this polymorphism was not observed in a Japanese population [11], suggesting that the frequency of the c. $1157 \mathrm{C}>\mathrm{T}$ polymorphism is relatively low and may play a minor role in Asian populations.

Other polymorphisms tested at c.1457C $>\mathrm{T}$, c.935C $>\mathrm{T}$ and c.601G $>$ A exhibited large differences in 
Fig. 2 Representative pyrosequencing pyrograms for a $S L C O 2 B 1 * 2($ c. $1175 \mathrm{C}>\mathrm{T})$, b $S L C O 2 B 1 * 3($ c. $1457 \mathrm{C}>\mathrm{T})$, c multiplex c. $43 \mathrm{C}>\mathrm{T} /$ c. $935 \mathrm{G}>\mathrm{A}$ and $\mathbf{d}$ multiplex c. $601 \mathrm{G}>\mathrm{A} / \mathrm{c} .644 \mathrm{~A}>\mathrm{T}$ of the $S L C O 2 B 1$ gene
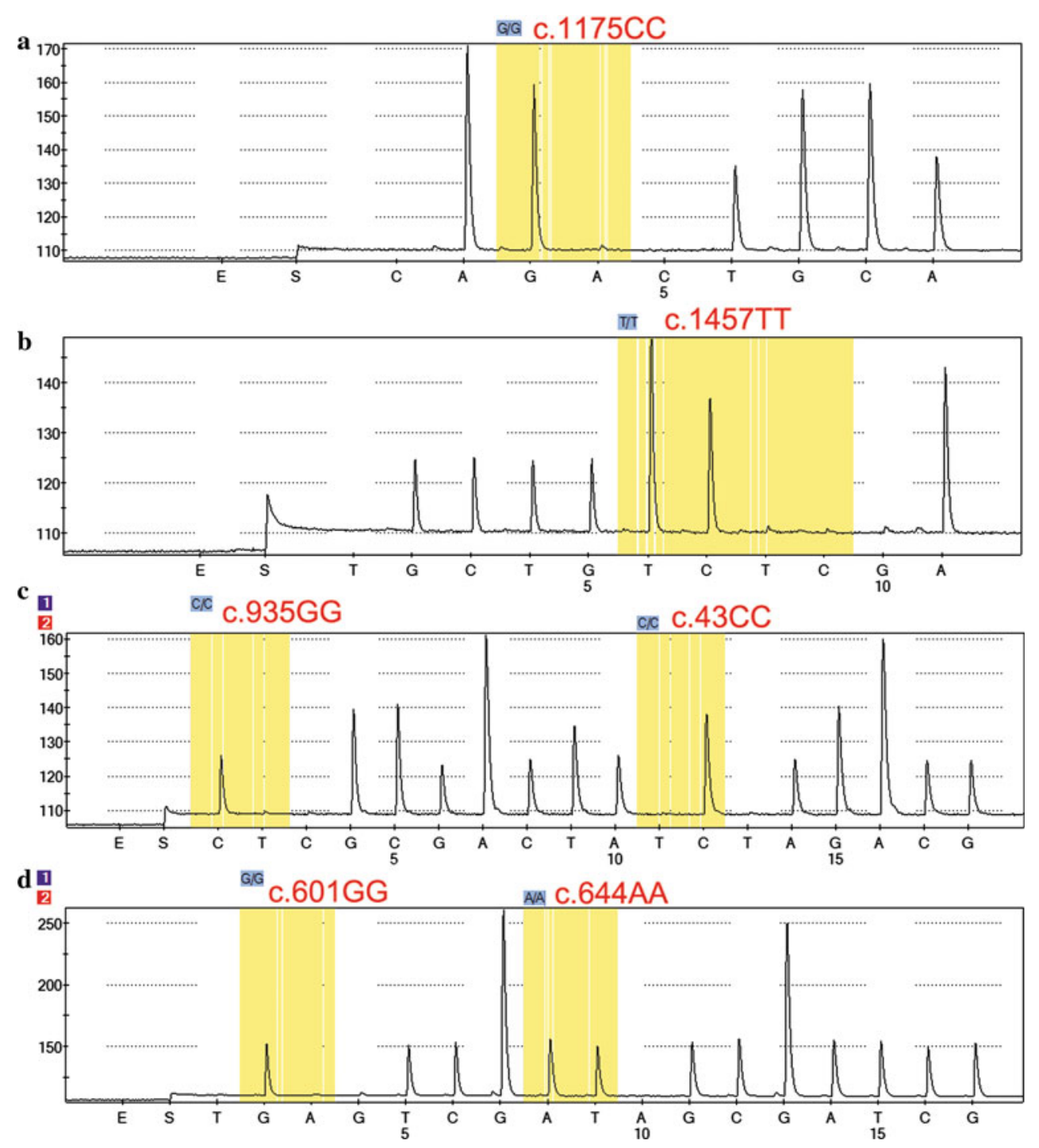

Table 3 Genotyping and allele frequencies of SLCO2B1 polymorphisms in this study

\begin{tabular}{llrlll}
\hline SNP & Genotype & No. & Frequencies & Allele & Frequencies \\
\hline c.1175C $>$ T & G/G & 227 & 1.0000 & G & 1.000 \\
c.1457C $>$ T & C/C & 128 & 0.5639 & $\mathrm{C}$ & 0.7313 \\
& C/T & 76 & 0.3348 & $\mathrm{~T}$ & 0.2687 \\
& T/T & 23 & 0.1013 & & \\
c.43C $>$ T & C/C & 227 & 1.0000 & $\mathrm{C}$ & 1.000 \\
c.933G $>$ A & G/G & 72 & 0.3172 & $\mathrm{G}$ & 0.5272 \\
& G/A & 116 & 0.5110 & $\mathrm{~A}$ & 0.4273 \\
& A/A & 39 & 0.1718 & & \\
c.601G $>$ A & G/G & 195 & 0.8590 & $\mathrm{G}$ & 0.9272 \\
& G/A & 31 & 0.1336 & $\mathrm{~A}$ & 0.0727 \\
c.644A $>$ T & A/A & 1 & 0.0004 & & \\
\hline
\end{tabular}

allele frequencies among ethnic groups. The frequencies of c. $1457 \mathrm{C}>\mathrm{T}$ and c. $601 \mathrm{G}>\mathrm{A}$ in a Finnish population were 2.8 and $2.1 \%$, respectively [1], while we observed frequencies of 26.9 and $7.3 \%$ for these two polymorphisms, respectively, in our Korean sample. Considering the allele frequency of c. $1457 \mathrm{C}>\mathrm{T}$ was $30.9 \%$ in a Japanese population [20], there seems to be large ethnic variability in the frequencies of $S L C O 2 B 1$ polymorphisms.

Intriguingly, the occurrence of the c.935G $>$ A polymorphism was less than $15 \%$ in Finnish $(13.60 \%)$, African-American (13.16\%) and Caucasian $(8.18 \%)$ populations, but we observed a $42.73 \%$ allele frequency in our Korean participants. Among the six non-synonymous polymorphisms tested in this study, the c.935G $>$ A SNP showed the highest polymorphic frequency, and this was also the case in other ethnic groups. Even though the results are controversial [21], previous studies revealed that 
Table 4 Comparisons of $S L C O 2 B 1$ allele frequencies with those in other ethnic groups

\begin{tabular}{|c|c|c|c|}
\hline & Population & Frequency $(\%)$ & Reference \\
\hline \multirow[t]{2}{*}{ c. $1175 \mathrm{C}>\mathrm{T}$} & Korean $(\mathrm{n}=227)$ & 0.00 & $\begin{array}{r}\text { Present } \\
\text { study }\end{array}$ \\
\hline & Japan $(\mathrm{n}=534)$ & 0.00 & [11] \\
\hline \multirow[t]{3}{*}{ c. $1457 \mathrm{C}>\mathrm{T}$} & Korean $(\mathrm{n}=227)$ & 26.87 & $\begin{array}{r}\text { Present } \\
\text { study }\end{array}$ \\
\hline & Japanese $(\mathrm{n}=534)$ & 30.90 & [11] \\
\hline & Finnish $(\mathrm{n}=552)$ & 2.80 & [1] \\
\hline c. $43 \mathrm{C}>\mathrm{T}$ & Korean $(\mathrm{n}=227)$ & 100 & $\begin{array}{r}\text { Present } \\
\text { study }\end{array}$ \\
\hline \multirow[t]{4}{*}{ c. $935 \mathrm{G}>\mathrm{A}$} & Korean $(\mathrm{n}=227)$ & 42.73 & $\begin{array}{l}\text { Present } \\
\text { study }\end{array}$ \\
\hline & Finnish $(\mathrm{n}=552)$ & 13.60 & [1] \\
\hline & $\begin{array}{l}\text { African-American } \\
\quad(\mathrm{n}=20)\end{array}$ & 13.16 & [8] \\
\hline & Caucasian $(\mathrm{n}=55)$ & 8.18 & [8] \\
\hline \multirow[t]{2}{*}{ c. $601 \mathrm{G}>\mathrm{A}$} & Korean $(\mathrm{n}=227)$ & 7.27 & $\begin{array}{r}\text { Present } \\
\text { study }\end{array}$ \\
\hline & Finnish $(\mathrm{n}=552)$ & 2.10 & [1] \\
\hline c. $644 \mathrm{~A}>\mathrm{T}$ & Korean $(\mathrm{n}=227)$ & 0.00 & $\begin{array}{r}\text { Present } \\
\text { study }\end{array}$ \\
\hline
\end{tabular}

the $\mathrm{c} .935 \mathrm{G}>\mathrm{A}$ polymorphism influences the pharmacokinetics and pharmacodynamics of montelukast, a SLCO2B1 substrate, in humans. A comparison between patients with c.935GG and c.935GA exhibited substantial difference in montelukast concentrations and its efficacy $[8,22]$, suggests that those with 935AA might be affected more deleteriously in terms of montelukast treatment. Considering the large ethnic differences in SLCO2B1 polymorphisms observed in the current study and the evidence showing the modulating effect of SLCO2B1 on their substrates' plasma levels and efficacy [7, 8, 18], more studies are warranted to validate the role of genetic variation of $S L C O 2 B 1$ in the pharmacokinetics and pharmacodynamics of SLCO2B1 substrates.

\section{Conclusion}

The developed pyrosequencing method is a rapid and reliable genotyping method to detect six non-synonymous SLCO2B1 polymorphisms. A large difference in SLCO2B1 genetic polymorphisms was noted when comparing our Korean sample with other ethnic groups. The SLCO2B1 polymorphisms at c. $1175 \mathrm{C}>\mathrm{T}, \mathrm{c} .43 \mathrm{C}>\mathrm{T}$ and c.644A $>$ $\mathrm{T}$ were not found in our Korean population, but c.1457C $>\mathrm{T}$, c. $935 \mathrm{G}>\mathrm{A}$ and c.601G $>\mathrm{A}$ exhibited higher frequencies in Koreans population than in Finnish, Caucasian and African-American populations.
Acknowledgments This study was supported by a grant from the Korea University College of Medicine (R\&D Activation Research Fund 2011) and a grant from the National Project for Personalized Genomic Medicine (A11218-11-PG02), Korea Health 21 R\&D Project, Ministry for Health, Welfare and Family Affairs, Republic of Korea.

Open Access This article is distributed under the terms of the Creative Commons Attribution License which permits any use, distribution, and reproduction in any medium, provided the original author(s) and the source are credited.

\section{References}

1. Laitinen A, Niemi M (2011) Frequencies of single-nucleotide polymorphisms of SLCO1A2, SLCO1B3 and SLCO2B1 genes in a Finnish population. Basic Clin Pharmacol Toxicol 108(1):9-13

2. Tamai I, Nozawa T, Koshida M, Nezu J, Sai Y, Tsuji A (2001) Functional characterization of human organic anion transporting polypeptide B (OATP-B) in comparison with liver-specific OATP-C. Pharm Res 18(9):1262-1269

3. Tamai I, Nezu J, Uchino H, Sai Y, Oku A, Shimane M, Tsuji A (2000) Molecular identification and characterization of novel members of the human organic anion transporter (OATP) family. Biochem Biophys Res Commun 273(1):251-260

4. Kullak-Ublick GA, Ismair MG, Stieger B, Landmann L, Huber R, Pizzagalli F, Fattinger K, Meier PJ, Hagenbuch B (2001) Organic anion-transporting polypeptide B (OATP-B) and its functional comparison with three other OATPs of human liver. Gastroenterology 120(2):525-533

5. Pizzagalli F, Varga Z, Huber RD, Folkers G, Meier PJ, St-Pierre MV (2003) Identification of steroid sulfate transport processes in the human mammary gland. J Clin Endocrinol Metab 88(8): 3902-3912

6. Nakanishi T, Tamai I (2012) Genetic polymorphisms of OATP transporters and their impact on intestinal absorption and hepatic disposition of drugs. Drug Metab Pharmacokinet 27(1):106-121

7. Imanaga $J$, Kotegawa $T$, Imai $H$, Tsutsumi $K$, Yoshizato $T$, Ohyama T, Shirasaka Y, Tamai I, Tateishi T, Ohashi K (2011) The effects of the SLCO2B1 c.1457C $>\mathrm{T}$ polymorphism and apple juice on the pharmacokinetics of fexofenadine and midazolam in humans. Pharmacogenet Genomics 21(2):84-93

8. Mougey EB, Feng H, Castro M, Irvin CG, Lima JJ (2009) Absorption of montelukast is transporter mediated: a common variant of OATP2B1 is associated with reduced plasma concentrations and poor response. Pharmacogenet Genomics 19(2):129-138

9. Ieiri I, Doi Y, Maeda K, Sasaki T, Kimura M, Hirota T, Chiyoda T, Miyagawa M, Irie S, Iwasaki K, Sugiyama Y (2012) Microdosing clinical study: pharmacokinetic, pharmacogenomic (SLCO2B1), and interaction (grapefruit juice) profiles of celiprolol following the oral microdose and therapeutic dose. J Clin Pharmacol 52(7):1078-1089

10. Ho RH, Tirona RG, Leake BF, Glaeser H, Lee W, Lemke CJ, Wang Y, Kim RB (2006) Drug and bile acid transporters in rosuvastatin hepatic uptake: function, expression, and pharmacogenetics. Gastroenterology 130(6):1793-1806

11. Nozawa T, Nakajima M, Tamai I, Noda K, Nezu J, Sai Y, Tsuji A, Yokoi T (2002) Genetic polymorphisms of human organic anion transporters OATP-C (SLC21A6) and OATP-B (SLC21A9): allele frequencies in the Japanese population and functional analysis. J Pharmacol Exp Ther 302(2):804-813

12. Masuda S, Ibaramoto K, Takeuchi A, Saito H, Hashimoto Y, Inui KI (1999) Cloning and functional characterization of a new 
multispecific organic anion transporter, OAT-K2, in rat kidney. Mol Pharmacol 55(4):743-752

13. Kalliokoski A, Niemi M (2009) Impact of OATP transporters on pharmacokinetics. Br J Pharmacol 158(3):693-705

14. Ronaghi M, Uhlen M, Nyren P (1998) A sequencing method based on real-time pyrophosphate. Science 281(5375):363-365

15. Pati N, Schowinsky V, Kokanovic O, Magnuson V, Ghosh S (2004) A comparison between SNaPshot, pyrosequencing, and biplex invader SNP genotyping methods: accuracy, cost, and throughput. J Biochem Biophys Method 60(1):1-12

16. Kim KA, Song WK, Kim KR, Park JY (2010) Assessment of CYP2C19 genetic polymorphisms in a Korean population using a simultaneous multiplex pyrosequencing method to simultaneously detect the CYP2C19*2, CYP2C19*3, and CYP2C19*17 alleles. J Clin Pharm Ther 35(6):697-703

17. Kim KA, Joo HJ, Park JY (2010) ABCG2 polymorphisms, $34 \mathrm{G}>\mathrm{A}$ and $421 \mathrm{C}>\mathrm{A}$ in a Korean population: analysis and a comprehensive comparison with other populations. J Clin Pharm Ther 35(6): 705-712

18. Miura M, Satoh S, Inoue K, Kagaya H, Saito M, Inoue T, Suzuki $\mathrm{T}$, Habuchi $\mathrm{T}$ (2007) Influence of SLCO1B1, 1B3, 2B1 and
ABCC2 genetic polymorphisms on mycophenolic acid pharmacokinetics in Japanese renal transplant recipients. Eur J Clin Pharmacol 63(12):1161-1169

19. Hagenbuch B, Meier PJ (2004) Organic anion transporting polypeptides of the OATP/SLC21 family: phylogenetic classification as OATP/SLCO superfamily, new nomenclature and molecular/functional properties. Pflugers Arch 447(5):653-665

20. Nozawa T, Imai K, Nezu J, Tsuji A, Tamai I (2004) Functional characterization of $\mathrm{pH}$-sensitive organic anion transporting polypeptide OATP-B in human. J Pharmacol Exp Ther 308(2): 438-445

21. Tapaninen T, Karonen T, Backman JT, Neuvonen PJ, Niemi M (2013) SLCO2B1 c.935G > A single nucleotide polymorphism has no effect on the pharmacokinetics of montelukast and aliskiren. Pharmacogenet Genomics 23(1):19-24

22. Mougey EB, Lang JE, Wen X, Lima JJ (2011) Effect of citrus juice and SLCO2B1 genotype on the pharmacokinetics of montelukast. J Clin Pharmacol 51(5):751-760 